\title{
Sex and Sentencing Disparity in South Australia's Higher Courts
}

\author{
Samantha Jeffries and Christine E W Bond*
}

\begin{abstract}
In Australia, studies examining sex differences in sentencing are limited. Using data from South Australia's higher courts, this article explores a study on the impact of sex on the decision to imprison and the length of imprisonment. After adjusting for past and current criminality, results showed that men were significantly more likely than women to be sentenced to a term of imprisonment and that when sentence length was decided, men received longer periods of incarceration. Furthermore, the study's results suggest that different factors may be important in determining sentencing outcomes for women and men.
\end{abstract}

\section{Introduction}

Over 50 years ago, Otto Pollak (1950) claimed in his book, The Criminality of Women, that female offenders were preferentially treated in the criminal justice system, as it was dominated by men and, thus, characterised by male notions of chivalry. Pollak presumed that offending women were placed on pedestals, treated gallantly and protected from punishment, with the result that their criminal activity was treated more leniently within the criminal justice system (Tjaden and Tjaden 1981).

Indeed, Australian court data shows that women are less likely to receive sentences of imprisonment. For example, from 2007 to 2008, 63.3\% of male offenders sentenced in Australia's higher courts received a custodial term in a correctional institution ${ }^{1}$ compared with only $46.7 \%$ of females (Australian Bureau of Statistics 2009a). Once sentenced to prison, Australian women, as a group (in general), also receive shorter terms of imprisonment than men. For instance, the mean aggregate sentence length for female prisoners in 2008 was 42.4 months while for men it was 60.3 months (Australian Bureau of Statistics 2009b).

One possible interpretation of the above data is that criminal courts treat women more leniently than men. Alternatively, disparity in sentencing outcomes may simply be a

* Dr Samantha Jeffries, Lecturer, School of Justice, Queensland University of Technology, Brisbane, Australia, email: s.jeffries@qut.edu.au; Dr Christine E W Bond, Lecturer, School of Social Science, University of Queensland, Brisbane, Australia, email: chris.bond@uq.edu.au. This study would not have been possible without the support of the South Australian Office of Crime Statistics and Research.

1 'Sentences imposed on a defendant requiring a person to be detained within a facility built especially for the purpose of incarceration. Includes: life and indeterminate imprisonment, imprisonment with determined term, imprisonment with partially suspended term, periodic detention, juvenile detention with determined term, and juvenile detention with partially suspended term' (Australian Bureau of Statistics 2009a). 
response to sex differences in offending behaviours. Judges' sentencing decisions are known to be driven by a number of focal concerns, including offender blameworthiness, harm caused by the offence and community protection (ie risk posed by an offender to the community in the future) (Johnson 2003; Steffensmeier, Ulmer and Kramer 1998). The seriousness of an offender's crime and their past criminal behaviour are vital to judicial assessments of blameworthiness, harm and risk (Steffensmeier, Ulmer and Kramer 1998:766-7). Sentencing research indicates that there is a strong correlation between the seriousness of the offender's criminal history, the severity of the offender's crime(s) and sentencing outcomes. Offenders with more extensive and more serious forms of criminality tend to receive harsher sentences because they are perceived as more blameworthy, have caused more harm and pose a greater risk to the community in the future (Mitchell 2005; Spohn 2000).

Sex differences in criminality might, therefore, explain why men receive more severe punishments than women (Daly 1994; Steffensmeier, Kramer and Streifel 1993). Criminal justice data shows the nature and extent of women's law breaking is different from men's. Women generally offend less often than men do and their crimes tend to be less serious. For example, Australian police data shows that between 1996 and 2007, men were three to four times more likely than women to be identified as offenders: women's rates of offending during 2006-07 were 747 per 100,000 compared with a male rate of 2,699 (Australian Institute of Criminology 2009:53). Further, men are more likely than women to commit crimes of serious violence (ie homicide, sexual assault, robbery) (Australian Institute of Criminology 2009:55-6). Discriminating between the sex differences in past and current offending and preferential treatment has been, and remains, a key issue for research on sex and sentencing outcomes.

\section{Previous research on sex differences in sentencing}

Outside of Australia, the question of sex differences in sentencing has been the subject of decades of extensive investigation, with the majority of studies being conducted in North America. In these studies, it is now standard to use multivariate analytic techniques like regression analysis to estimate the separate independent impact (direct effect) of sex on sentencing by controlling for other relevant sentencing variables (such as current and past criminality). The purpose here is to ascertain whether or not initial sex differences in sentencing can be attributed to differences in crime seriousness, prior criminal record, or other legally relevant factors. Sentencing researchers have also utilised multivariate analyses to establish whether or not sex interacts with other factors to influence the sentencing decision. In this case, the question is whether different sentencing determinates are weighted differently by sex.

In terms of direct effects, international sentencing studies generally show that women receive less serious sentencing outcomes than men (eg are less likely to be imprisoned) even when current and past criminality are held constant. In their extensive review of statistical sentencing studies worldwide, Daly and Bordt (1995) found that the majority of high quality analyses find sex differences that 'favoured' women over men. Differences between men and women with regard to sentence severity (eg imprisonment versus non-custodial sentence) were found to be in the range of $8-25 \%$, with women's sentences being less severe than men's. Incarceration periods also varied, with men being sentenced on average about 12 months longer than women when appearing before the courts under supposedly similar circumstances. 
International research also shows that different factors are sometimes considered when determining men's and women's sentencing outcomes. Sex is often found to interact with current and past criminality to the detriment of men. For example, Nagel (1981:112) found that offence severity and criminal history had no significant effect on the likelihood of incarceration for women, but men were adversely affected by these factors. For male offenders, the commission of a serious offence and/or the presence of prior convictions significantly increased the likelihood of an imprisonment sentence. In contrast, Steffensmeier, Kramer and Streifel (1993:432) found that the effects of these legal factors were essentially the same for both male and female offenders. More recently, Spohn and Beichner's (2000:170) analyses of sentencing showed that 'although legally relevant variables' - namely, current crime seriousness and measures of prior criminality 'produce the predicted effects on incarceration regardless of sex, overall, these variables more consistently affect the likelihood of incarceration for men than for women'.

\section{Prior Australian and New Zealand research}

Compared with North America, little systematic research on the relationship between sex and sentencing has been conducted in Australasia. Between Australia and New Zealand, a search of past research produced only five published studies on sex and sentencing. Combined, these studies suggest that the sex of an offender may have a direct and interactive effect on sentencing outcomes.

\section{New Zealand}

In New Zealand, there have been two methodologically robust studies exploring the relationship between sex and sentencing (see Triggs 1999; the findings of the second study have been published in Jeffries 2002a, 2002b, 2004 and Jeffries, Fletcher and Newbold 2003). Results from both investigations mirror the general findings of North American research.

Triggs (1999) investigated the direct relationship between sex and sentencing. After controlling for a large number of legal variables (including current and past criminality), it was found that men were more likely than women to be imprisoned (Triggs 1999:123). Jeffries' (2002a, 2002b, 2004) study of sex differences in sentencing found further evidence that in comparison to men, women receive less serious sentencing outcomes. In this case, sex was found to have a direct impact on the length of imprisonment term. Despite sex differences in legal variables such as seriousness of criminal history and current crime seriousness, women's imprisonment terms were approximately 8.5 months shorter than men's (Jeffries 2002b:28; Jeffries, Fletcher and Newbold 2003). In addition to this direct sex effect, the decision-making process was also differentiated by sex (interactive effect). Legal variables were more likely to increase men's sentences compared to women's. For example, criminal history seriousness was found to aggravate men's sentencing outcomes more than women's (Jeffries 2004:290).

\section{Australia}

In Australia, published research examining the relationship between sex and sentencing in the adult courts is limited to three studies of the lower courts, conducted over a decade ago. In a comparison of the sentencing of male and female offenders in the Magistrates' Court of Victoria, Naylor $(1991,1993)$ found that, after controlling for offence seriousness and prior criminal record, women received lighter fines for certain types of offences. This was the only sex-based sentencing difference found. Similarly, in an earlier study, Douglas (1987) found that women in Victorian Magistrates' Court were fined less than men in some 
instances, net of prior convictions, number of charges, type of offence and offence seriousness. Douglas (1987:354) suggests that this sex difference in fine amount may be indicative of 'assumptions about the relative capacity to pay of female defendants in general'. Although unable to be tested due to the low number of females in his study, Douglas (1987:355) did not rule out the possibility that 'female defendants may have been sentenced according to different criteria to those used to sentence males'. Finally, Lawrence and Homel's (1992:400) analyses of sentencing discrimination amongst a sample of drink drivers in two magistrates' courts also found that male drivers were treated more harshly than female drivers, receiving, on average, fines $9.7 \%$ higher, and disqualification periods $22.2 \%$ longer.

\section{The current study}

In summary, past research investigating the relationship between sex and sentencing suggests both direct and interactive effects. First, women are less likely to be imprisoned and, once sentenced to a prison term, receive shorter periods of incarceration (direct effect). Second, compared with women, variables measuring current and past offending behaviour appear more likely to aggravate the sentences of men (interactive effect).

Australian sentencing research is limited to three dated studies, exploring lower court outcomes where sentences of imprisonment are infrequent. The current study investigates the direct and interactive influence of sex on sentencing in the higher courts in one Australian jurisdiction. Using recent sentencing data (2002-06) from the higher courts (the District Court and the Supreme Court) of South Australia, three research questions are examined:

1. Are women, on average, less likely than men to receive a sentence of imprisonment for comparable offending behaviour and histories?

2. Do women receive, on average, shorter terms of imprisonment than men for comparable offending behaviours and histories?

3. Are offending behaviours and histories weighted differently by sex when deciding sentencing outcomes?

\section{Method}

South Australian data from both the District Court and the Supreme Court was analysed. In this jurisdiction, more serious crimes (indictable offences) are sentenced by judges in the Supreme and District Courts. The court data was sourced from the database maintained by the Office of Crime Statistics and Research (OCSAR) with the Attorney-General's Department of the Government of South Australia, which tracks cases through the court system. Unlike some administrative databases, OCSAR's is particularly reliable in that there was little, if any, missing data and past experience with this database suggested few coding errors (see Jeffries and Bond 2009). However, this study is limited to the information that OCSAR has decided collect. 
In total, data was obtained for 3,741 offenders $^{2}$ who were convicted in the higher courts during 2002-06. Of these, about $87.97 \%$ were male and $10.23 \%$ were identified as indigenous. The average age of offenders was 30.89 years at the time of sentencing. About $44.47 \%$ received a sentence of imprisonment, with an average length of 48.06 months. Fifty-four offenders convicted of offences with statutorily prescribed mandatory life sentences, and, consequently no discretion in outcome, were not included in our analysis.

Table 1 provides a description of the variables used in this study. There are two main groups of independent variables. In addition to an offender's sex, the first group contains offender characteristics, including indigenous status and age. Sentencing decisions are affected by judicial perceptions of an offender's ability to 'do time', but can also be influenced by criminal stereotyping (Johnson 2003; Steffensmeier, Ulmer and Kramer 1998). Age and indigenous status can be important in deciding whether a sentence of imprisonment may be unduly harsh. For example, younger people could be perceived as less able to cope with imprisonment and also more amenable to rehabilitation (Wu and Spohn in press). Australian research also suggests that judges may perceive incarceration to be especially stressful for indigenous people (Jeffries and Bond 2009). At the same time, and somewhat paradoxically, criminality (or the threat of criminality) is often associated with youthfulness and ethnic minority groups (Steffensmeier, Ulmer and Kramer 1998; White and Perrone 2005). This means that being younger and from an ethnic minority group could potentially increase the chances of imprisonment. This makes controls for both age and indigenous status especially important.

The second group of independent variables consists of case characteristics: seriousness of the principal offence, conviction counts, prior criminal history, and guilty plea. When making sentencing decisions, judges must impose punishment proportionate to the criminal harm caused, while also taking into consideration how culpable offenders are for their actions and any potential risks they pose to the community (Steffensmeier, Ulmer and Kramer 1998; White and Perrone 2005). As noted previously, current crime seriousness and criminal history are crucial to these considerations (Mitchell 2005; Spohn 2000).

In Australia, offence seriousness is codified in law using statutory offence classifications and prescribed sentencing penalties. This study used the National Offence Index (NOI) to measure the seriousness of an offender's principal offence. The NOI, developed by the Australian Bureau of Statistics, ranks the seriousness of all offence classifications in the Australian Standard Offence Classification System - a numerical codification and systematic ordering of offences defined, either implicitly in the common law or explicitly in Australian legal codes (Australian Bureau of Statistics 1997). The NOI ranking ranges from 1 to 155 , with 1 being the most serious and 155 being the least serious. To assist in the interpretation of the findings, this was reverse-coded, so that higher scores indicate more serious offences. The number of conviction counts was included as an additional measure of current crime seriousness. Prior criminal history was measured by an additive standardised index that combined: the number of prior criminal convictions; the number of prior convictions in the same offence category as the current convicted offence; and number of prior imprisonment terms (Cronbach's alpha $=0.87$ ). Finally, pleading guilty may not only be

This study examines the sentencing outcomes for cases, rather than individual offenders, because the administrative data does not contain a unique identifier for individual offenders, and is not structured in such a way to allow for the unique identification of individual offenders. It was only possible to distinguish between events involving the same offender that occurred on the same day. Thus, some individuals may appear more than once in the sample. However, the use of cases as the unit of analysis is common in sentencing disparities research. Although these are samples of cases, the term 'offender' will be used for ease of reference. 
perceived as a show of remorse by judges, but also be seen as saving the court time (Johnson 2003:454; Steffensmeier, Ulmer and Kramer 1998:767-8). A guilty plea was measured as a dummy variable, with ' 1 ' indicating that a guilty plea was entered.

Table 1: Description of study variables (South Australia, 2002-06)

\begin{tabular}{|c|c|c|}
\hline Variables & Description & $\begin{array}{l}\text { Summary } \\
\text { statistics }^{\mathrm{a}}\end{array}$ \\
\hline \multicolumn{3}{|l|}{ Independent variables } \\
\hline Sex & $0=$ female, $1=$ male & 0.88 \\
\hline Indigenous status & $0=$ non-indigenous, $1=$ indigenous & 0.10 \\
\hline Age & In years & $30.89(10.50)$ \\
\hline Seriousness of principal offence & $\begin{array}{l}\text { Reverse-coded National Offence Index } \\
\text { (NOI), with higher scores indicating more } \\
\text { serious offences. Developed by the Australian } \\
\text { Bureau of Statistics, the NOI ranks all offence } \\
\text { classifications in Australian Standard Offence } \\
\text { Classification System in order of seriousness. }\end{array}$ & $111.81(28.94)$ \\
\hline Conviction counts & $0=$ no other convictions, $1=$ other convictions & 0.61 \\
\hline Prior criminal history & $\begin{array}{l}\text { Sum of standardised z-scores for number of } \\
\text { prior criminal convictions, number of prior } \\
\text { criminal convictions in the same offence } \\
\text { category as the current offence, number of } \\
\text { prior imprisonment terms }\end{array}$ & $0.012(2.68)$ \\
\hline Plead guilty & $0=$ no $\mathrm{plea} /$ not guilty plea; $1=$ guilty plea & 0.63 \\
\hline \multicolumn{3}{|l|}{ Dependent variables } \\
\hline $\begin{array}{l}\text { Imprisonment sentencing } \\
\text { decision }\end{array}$ & $0=$ not imprisoned, $1=$ imprisoned & 0.44 \\
\hline Length of imprisonment term & In months & $48.06(41.66)^{\mathrm{b}}$ \\
\hline Total number of cases & & 3,741 \\
\hline
\end{tabular}

Notes:

a Means (with standard deviations in brackets) are reported for continuous variables; proportions are reported for categorical variables.

b $\quad \mathrm{N}=1,664$. Median length of imprisonment is 35.90 months. 
Sentencing outcomes - namely, the initial decision to imprison (actual, not suspended) and length of imprisonment term - were investigated over a five-year period from 2002 to 2006. This study used a logistic model to estimate the independent impact of sex on the decision to imprison (dichotomous dependent variable), and a negative binomial model for length of imprisonment term (dependent variable). Length of imprisonment has a highly skewed distribution in this sample; a mean of about 48.06 (months) and a variance of 1735.87 indicated over-dispersion. A negative binomial model (treating months as a count) fitted the non-normality of the length of imprisonment variable, with the likelihood ratio test confirming the negative binomial rather than the Poisson distributional form. In addition, the negative binomial model produces more interpretable coefficients than the more traditional Ordinary Least Squares model on a logged dependent variable (see also Jeffries and Bond 2009). All models controlled for the effect of: indigenous status; age at sentencing; seriousness of principal offence; presence of multiple conviction counts; and prior criminal history.

Due to lack of available data and estimation problems, the models do not adjust for selection bias - selection bias refers to the effect of the accumulation of decisions for offenders as they progress through the criminal justice system. In other words, the offenders in this study are present due to other earlier decisions (eg to arrest, to charge etc) decisions based on factors that are highly likely to be correlated with the decision of interest (eg imprisonment) (Bushway, Johnson and Slocum 2007). Thus, this study's inferences are limited to the population of convicted offenders (decision to imprison) and imprisoned offenders (length of imprisonment decision). Conclusions cannot necessarily be drawn about sex differences at other stages of the processing of offenders through the criminal justice system, nor completely account for the impact of previous decisions.

\section{Results}

This study explored the influence of sex of offenders on the sentencing outcomes, net of offender and case characteristics. Table 2 presents the descriptive statistics by sex for the variables used in the analyses. As appropriate, t-test and z-test statistics were calculated to examine any differences between means and proportions for male and female offenders.

Several statistically significant differences in the cases and characteristics of the female and male offenders are revealed in Table 2. More women were identified as indigenous than men $(16.90 \%$ cf $9.44 \%$ of male offenders); fewer had been convicted of multiple counts $(51.33 \%$ cf $62.72 \%$ of male offenders); and more women had entered a guilty plea $(69.78 \%$ cf $62.29 \%$ of male offenders). The female offenders were less likely to receive a sentence of imprisonment than the male offenders $(30.44 \%$ of $46.37 \%$, respectively), and once sentenced to imprisonment, received, on average, shorter terms of imprisonment (39.12 months cf 48.82 months, respectively). There were no statistically significant differences at conventional levels in the mean age at sentencing and mean offence seriousness between male and female offenders in this study. 
Table 2: Offender and case characteristics by sex (South Australia, 2002-06)

\begin{tabular}{|c|c|c|c|c|c|}
\hline & \multicolumn{2}{|c|}{ Female offenders } & \multicolumn{2}{|c|}{ Male offenders } & \multirow[t]{2}{*}{ Difference $^{b}$} \\
\hline & $\begin{array}{l}\text { Mean/ } \\
\text { proportion }^{\mathrm{a}}\end{array}$ & $\mathrm{N}$ & $\begin{array}{l}\text { Mean/ } \\
\text { proport }\end{array}$ & $\mathrm{N}$ & \\
\hline Indigenous status & 0.16 & 435 & 0.09 & 3231 & $0.07^{* * *}$ \\
\hline Age at sentencing & 31.46 & 450 & 30.82 & 3289 & 0.64 \\
\hline Offence seriousness & 109.53 & 450 & 112.11 & 3291 & $2.58^{\#}$ \\
\hline Multiple counts & 0.51 & 450 & 0.63 & 3291 & $0.11^{* * *}$ \\
\hline Prior criminal history & -0.29 & 436 & 0.05 & 3264 & $0.35^{*}$ \\
\hline Plead guilty & 0.70 & 450 & 0.62 & 3291 & $0.07^{* *}$ \\
\hline Imprisoned & 0.30 & 450 & 0.46 & 3291 & $0.16^{* * *}$ \\
\hline Length of term & 39.21 & 137 & 48.82 & 1526 & $9.70^{* * \mathrm{c}}$ \\
\hline
\end{tabular}

$\# \mathrm{p}<0.10 * \mathrm{p}<0.05 * * \mathrm{p}<0.01 * * * \mathrm{p}<0.001$

Notes:

a Means are reported for continuous variables; proportions are reported for categorical variables.

b T-scores (differences between means) and z-scores (differences between proportions) were calculated; $\mathrm{H}_{0}$ : the means/proportions for male and female offenders are the same; $\mathrm{H}_{\mathrm{a}}$ : the means/proportions are not equal.

c As length of term is skewed, a t-test for the difference between the means of male and female offenders on the logged form of the variable was also calculated. The results also suggest that there is a statistically significant difference between male and female offenders.

\section{Direct effect of sex on sentencing outcomes}

To explore the direct influence of sex, controlling for other case and offender characteristics, this study used logistic regression for the decision to imprison, and negative binomial regression for the length of term. ${ }^{3}$ The estimated coefficients, standard errors and odd ratios for the decision to imprison model are summarised in Table 3. The odds ratio (OR) represents the change in the likelihood of receiving a sentence of imprisonment for a unit change in the independent variable. For instance, an odds ratio of 1.002 implies that a sentence of imprisonment is more likely as the age of an offender increases. Table 3 also reports the estimated coefficients, standard errors and incident rate ratios for the length of imprisonment model. Incident rate ratios (IRR) are interpreted as a multiplier of the count, so an IRR of 1.01 means each year increase in age, increases the number of months of imprisonment by 1.01 .

As both these techniques rely on maximum likelihood estimation, standard fit statistics should not be interpreted independently. However, both models are a significantly better fit than the intercept only model (see chi-square statistics reported in Table 3). 
Table 3: Direct effects models of the decision to imprison and length of term (South Australia, 2002-06) ${ }^{\mathrm{a}}$

\begin{tabular}{l|lll||lll}
\hline & \multicolumn{5}{|c||}{ Decision to Imprison } & \multicolumn{3}{c}{ Length of Term $^{\mathrm{c}}$} \\
& $\mathrm{b}$ & s.e. & OR & $\mathrm{b}$ & s.e. & IRR \\
\hline Male & $0.549^{* * *}$ & 0.122 & 1.731 & $0.145^{*}$ & 0.065 & 1.156 \\
Indigenous status & $0.233^{\#}$ & 0.131 & 1.262 & $0.094^{\#}$ & 0.054 & 1.098 \\
Age at sentencing & 0.002 & 0.004 & 1.002 & $0.009^{* * *}$ & 0.002 & 1.009 \\
Offence seriousness & $0.014^{* * *}$ & 0.001 & 1.014 & $0.011^{* * *}$ & 0.001 & 1.011 \\
Multiple conviction counts & $0.903^{* * *}$ & 0.078 & 2.467 & $0.331^{* * *}$ & 0.040 & 1.392 \\
Criminal history & $0.304^{* * *}$ & 0.021 & 1.355 & -0.001 & 0.006 & 0.999 \\
Plead guilty & $-0.705^{* * *}$ & 0.076 & 0.494 & $-0.106^{* *}$ & 0.035 & 0.900 \\
& & & & & & \\
Intercept & $-2.453^{* * *}$ & 0.235 & & $1.988^{* * *}$ & 0.123 & \\
$\chi^{2}$ (d.f.) & & & & & & \\
Number of cases & $665.54(7)^{* * *}$ & & & & & \\
\hline
\end{tabular}

$\# p<0.10 * \mathrm{p}<0.05 * * \mathrm{p}<0.01 * * * \mathrm{p}<0.001$

Notes:

a Models were estimated with a series of dummy variables to adjust for the year of sentence. For the decision-toimprison model, there was only one significant estimate (at $\mathrm{p}<0.05$ ) found between 2002 (reference year) and the other years $(2003,2004,2005,2006)$ : the year 2005. For the length-of-term model, there were no significant coefficients for year. In both models, the direction of estimated coefficients and patterns of significance for the independent variables of interest did not change. Models without adjusting for year of sentence are reported.

b Table reports logistic regression results for the decision to imprison.

c Table reports negative binomial regression results for the length of term.

There are four findings that should be noted. First, sex has a statistically significant direct effect on the decision to imprison (see Table 3). After controlling for other offender and case characteristics, particularly past and current offending, offenders who are male are, on average, 1.73 times as likely to receive a sentence of imprisonment, compared to female offenders. Sex also had a statistically significant direct effect on the length of imprisonment (see Table 3). Second, although not a large effect, being male increased the number of months of imprisonment by 1.16 . Thus, consistent with the findings of past research, men receive harsher sentencing outcomes than women in similar circumstances.

Third, the effect of indigenous status is not statistically significant at the conventional level of $\mathrm{p}<0.05$ in either the decision to imprison or the length of imprisonment models 
(see Table 3). Nonetheless, offenders who are identified as indigenous are, on average, 1.26 times as likely to receive a sentence of imprisonment as non-indigenous offenders, independent of other variables in the model. Although this finding fails to reach significance, it may require some consideration, as it appears to be contrary to recent research in this jurisdiction, which found that indigenous status reduced the odds of imprisonment (see Jeffries and Bond 2009). The analysis reported here was on all offenders convicted in South Australia's higher courts during the period 2002-06. Jeffries and Bond's (2009) prior research was based on a smaller matched sample of offenders $(n=296)$ sentenced over a one-year period (2005-06). This raises the possibility that the impact of indigenous status on sentencing in South Australia's higher courts may have been varying over time. Further, the current analyses does not contain information on other factors - such as experiences of victimisation, remand status and context of current offending - that were available for the smaller sample of offenders analysed by Jeffries and Bond (2009). Better controls for offence seriousness and criminal history were also possible in the earlier study. As these factors may be differentially distributed by indigenous status, indigenous status in this model could be capturing some of the effects of these other variables, resulting in a different direction of effect. Further, as indigenous offenders constitute around $10 \%$ of the total study sample, there may be insufficient power to detect moderate to small effect sizes.

Fourth, the influence of case characteristics largely conforms to the expectations of prior research. Current and past criminality increases the likelihood of a decision to imprison, net of other variables in the model. Offence seriousness $(\mathrm{OR}=1.01),{ }^{4}$ the presence of multiple conviction counts $(\mathrm{OR}=2.47)$, and prior criminal history $(\mathrm{OR}=1.36)$ have statistically significant direct effects on the decision to imprison. Further, a guilty plea reduces the risk of imprisonment: those who entered a guilty plea were, on average, 0.49 times as likely to receive a sentence of imprisonment, after adjusting for other case and offender characteristics.

Similarly, current and past criminality increases the length of imprisonment, after controlling for other variables in the model. The presence of multiple conviction counts had the strongest effect on the length of imprisonment (IRR=1.39). The entry of a guilty plea reduced the length of imprisonment (IRR $=0.90)$, consistent with a perception that signs of remorse mitigate the sentencing decision. However, prior criminal history did not have a statistically significant effect on the length of imprisonment term, suggesting that, at this later sentencing stage, judges may be thinking in terms of proportionality to current offence, rather than risk to the community.

\section{Differential effects by sex on sentencing outcomes}

This analysis shows that sex has a sizeable significant direct effect on the decision to imprison, and a small significant direct effect on length of imprisonment term. The further question is whether the effects of other factors, like past and current criminality, are differentially weighted by sex. Thus, the model for the decision to imprison was reestimated separately for male and female offenders. Due to sample size issues (137 female offenders), the model was not re-estimated by sex for length of imprisonment.

To test whether the estimated coefficients for the male model of the decision to imprison were significantly different from those estimated in the female model, this study first estimated the original model with interaction terms for: sex and indigenous status; sex and

4 Remember that offence seriousness is measured on a scale ranging from 1 to 155 . 
age; sex and offence seriousness; sex and multiple conviction counts; sex and prior criminal history; and sex and plea of guilt. The addition of interaction terms to the direct effects model significantly improved the fit of the model $\left(\Delta \chi^{2}=23.17\right.$; d.f. $\left.=6 ; \mathrm{p}<0.001\right)$.

The results of these analyses are presented in Table 4, and in two forms to assist in interpretation. The first panel in Table 4 shows the results for the full interaction model, showing both direct and interactive effects separately. The odds ratios for the interaction terms show the effect on the sentencing outcome for a female offender, over and above the effect for a male offender (holding constant all other factors in the model). The second panel presents the results for the separate models for male and female offenders. The odds ratios in these models provide the 'full' impact (or combined direct and interaction effects) of sex on the sentencing outcome.

Compared to the direct effects model of the decision to imprison, the direction of the estimated effects of the variables does not change in the models for male and female offenders (see Table 4). On average, past and current criminality increases the likelihood of imprisonment in both the male and female models; the presence of a guilty plea reduced the likelihood of imprisonment in both models. However, the strength of the effect differs by sex. For instance, controlling for the other variables in the model, criminal history was given greater weight in the decision to imprison for male offenders $(\mathrm{OR}=1.39$, see male only model, Table 4) compared with female offenders $(\mathrm{OR}=1.14$, see female only model, Table 4). In contrast, the presence of multiple conviction counts is weighted more strongly for female offenders $(\mathrm{OR}=4.18$, see female only model, Table 4) than male offenders $(\mathrm{OR}=2.34$, see male only model, Table 4). Similarly, although not a statistically significant difference between the male and female models, male offenders who plead guilty are 0.48 times as likely to receive a sentence of imprisonment (see male only model, Table 4); female offenders who plead guilty are 0.613 times as likely to receive a sentence of imprisonment (see female only model, Table 4).

These results suggest that sentencing judges may perceive past and current criminality differently for male and female offenders. 
Table 4: Interactive effects models (logistic results) of the decision to imprison (South Australia, 2002-06)

\begin{tabular}{|c|c|c|c|c|c|c|c|c|c|}
\hline & \multicolumn{3}{|c|}{ All offenders ${ }^{a}$} & \multicolumn{3}{|c|}{ Female offenders } & \multicolumn{3}{|c|}{ Male offenders } \\
\hline & $\mathrm{b}$ & s.e. & OR & $b$ & s.e. & OR & $\mathrm{b}$ & s.e. & OR \\
\hline Male & -0.427 & 0.659 & 0.653 & - & - & - & - & - & - \\
\hline Indigenous status & $0.596^{\#}$ & 0.314 & 1.826 & $0.596^{\#}$ & 0.314 & 1.816 & 0.153 & 0.144 & 1.165 \\
\hline Age at sentencing & -0.013 & 0.012 & 0.987 & -0.013 & 0.012 & 0.987 & 0.004 & 0.004 & 1.004 \\
\hline Offence seriousness & 0.005 & 0.004 & 1.005 & 0.005 & 0.004 & 1.005 & $0.015^{* * *}$ & 0.002 & 1.015 \\
\hline Multiple conviction counts & $1.431^{* * *}$ & 0.244 & 4.181 & $1.431^{* * *}$ & 0.244 & 4.181 & $0.848^{* * *}$ & 0.082 & 2.335 \\
\hline Criminal history & $0.135^{* *}$ & 0.049 & 1.144 & $0.135^{* *}$ & 0.049 & 1.144 & $0.331^{* * *}$ & 0.023 & 1.392 \\
\hline Plead guilty & $-0.490^{*}$ & 0.248 & 0.613 & $-0.490^{*}$ & 0.248 & 0.613 & $-0.742^{* * *}$ & 0.080 & 0.476 \\
\hline Sex*Indigenous status & -0.444 & 0.345 & 0.642 & - & - & - & - & - & - \\
\hline Sex*Age & 0.017 & 0.013 & 1.017 & - & - & - & - & - & - \\
\hline Sex*Offence seriousness & $0.010^{*}$ & 0.005 & 1.010 & - & - & - & - & - & - \\
\hline Sex*Multiple counts & $-0.582^{*}$ & 0.257 & 0.559 & - & - & - & - & - & - \\
\hline Sex $*$ Criminal history & $0.196^{* * *}$ & 0.054 & 1.217 & - & - & - & - & - & - \\
\hline Sex*Guilty plea & -0.252 & 0.261 & 0.778 & - & - & - & - & - & - \\
\hline Intercept & $-1.559^{*}$ & 0.622 & & $-1.559^{*}$ & 0.622 & & $-1.986^{* * *}$ & 0.218 & \\
\hline$\chi^{2}$ (d.f.) & \multicolumn{3}{|c|}{$688.71(13)^{* * *}$} & \multicolumn{3}{|c|}{$64.70(6)^{* * *}$} & \multicolumn{3}{|c|}{$582.91(6)^{* * *}$} \\
\hline Number of cases & \multicolumn{3}{|c|}{3628} & \multicolumn{3}{|c|}{423} & \multicolumn{3}{|c|}{3205} \\
\hline
\end{tabular}

$\# \mathrm{p}<0.10 * \mathrm{p}<0.05 * * \mathrm{p}<0.01 * * * \mathrm{p}<0.001$

Note: a Adding the interaction terms to the direct effects model (presented in Table 3) improved the fit of the model $\left(\Delta \chi^{2}=23.17 ;\right.$ d.f. $=6$; $\left.p<0.001\right)$. 


\section{Summary and discussion}

This research examined the direct and interactive effect of sex on sentencing in South Australia's District and Supreme Courts over a period of five years (2002-06). Consistent with official criminal justice data, women's offending behaviours tended to be less serious than men's, but even when these factors were controlled, women were sentenced more leniently than men. A direct relationship between sex and sentencing was found: when women and men appeared before South Australia's higher courts for comparable criminality (past and present), women were less likely to be imprisoned and, when sentenced to prison received shorter terms.

Possible explanations for the finding of a direct sex effect may rest on actual and/or perceived differences in social circumstances of men and women, as well as factors associated with the court process. As noted earlier, judges' sentencing decisions are known to be driven by a number of focal concerns including offender blameworthiness and risk (Johnson 2003; Steffensmeier, Ulmer and Kramer 1998). Research shows that personal histories of abuse and victimisation (both in childhood and adulthood) and poor physical and mental health (including substance abuse/misuse) may mitigate sentences, as they may change judicial assessments of the offender's level of culpability (White and Perrone 2005:155; see also Allen 1987; Jeffries 2002a, 2002b). Further, strong familial ties (including having the responsibility for the care of others) indicate increased levels of informal social control in an offender's life. The presence of high levels of informal social control reduces re-offending risks and may, therefore, lessen the need to impose formal control via sentencing (Daly 1987a, 1987b, 1989, 1994; Jeffries 2002a, 2002b; Jeffries, Fletcher and Newbold 2003; Kruttschnitt 1982, 1984; Kruttschnitt and Green 1984). The social cost of removing primary caregivers (usually mothers) from their families is also found to mitigate sentencing outcomes (Daly 1989; Jeffries, 2002a, 2002b).

Researchers in both North America and Australasia have found that women's sentencing is significantly impacted by victimisation experiences, health and familial circumstances. For example, in an analysis of judges sentencing remarks in New Zealand, Jeffries (2002b) found that compared with men, judicial perceptions of female offenders as familial nurturers and dependants, as pathological, and as victims of a plethora of traumatic life experiences could explain sentencing leniency. In the North America, Frazier, Bock and Henretta (1983:315) found that sex differences favouring women dissipated once pre-sentence report recommendations were added to the analysis. Further investigation showed imprisonment recommendations were less likely for women because strained familial relationships (including abuse) and/or mental health problems were seen to explain their offending. In Western Australia, Wilkie's (1993) analyses of pre-sentence reports found that in contrast to men, women convicted of violent or drug offences were more likely to be mentally pathologised (eg mental health problems). This resulted in less punitive and more rehabilitative sentencing recommendations being made for women. These pre-sentence recommendations were generally followed and suggest possible reasons for sex-based sentencing disparity.

For instance, Daly's (1987b:167) statistical analyses of pre-trial release decisions, sentencing and dismissals, found that 'net of case severity, charge severity, the type of offence charged, prior record, and other defendant characteristics, male and female defendants are treated differently on the basis of their ties to and responsibilities for others'. Men and women with strong familial ties and child care responsibilities were sentenced less severely than non-familied defendants. As these responsibilities are generally differentially 
distributed, female offenders are more likely to experience mitigation of sentencing outcomes for their family circumstances.

Although current and past offender behaviours are two of the most significant legal variables known to influence sentencing outcomes, there are also other court processing factors that have been found to impact sentencing, such as remand status. Refusal by police and previous judicial actors to release offenders back into the community may influence judges' perceptions of risk (Jeffries, Fletcher and Newbold 2003). Prior studies show that there is a direct relationship between sex and remand status, with women being less likely than men to receive custodial remand outcomes. For example, in their New Zealand sentencing research, Jeffries, Fletcher and Newbold (2003:348) found that sex differences in remand outcomes provided some of the explanation for why women were sentenced less harshly than men:

Although similar factors (e.g. seriousness of criminal history) influence [both remand and sentencing], the evidence here shows that sex-based decision making earlier in the process [ie remand] makes a unique contribution to sex-based outcomes later on [ie sentencing].

In the current study, it is therefore possible that if there was a control for remand outcomes, the direct relationship between sex and sentencing may have dissipated.

In addition to a direct effect of sex, this analysis found that sex interacted with other offender and case characteristics, at least for the decision to imprison. That is, past and current criminal behaviour, as well as the entry of a guilty plea, were differentially weighted by sex. As was the case with the finding of a direct sex effect on sentencing, explanations for these interaction effects may relate to gendered social variables that were not measured in the current study. For example, criminal history was found to be more detrimental for men's sentencing outcomes. It is possible that women's criminal histories may be downplayed at sentencing when they present with a plethora of negative life experiences, as well as strong familial ties including primary child care responsibilities.

Judicial assessments of case factors (such as guilty pleas) may also be affected by cultural expectations around gender and behaviour. Prior research has found that women's treatment within the criminal justice system may depend on the degree to which their behaviour (both criminal and non-criminal) can be reconciled within dominant gender discourses (Farrington and Morris 1983; Nagel 1981; Nagel, Cardascia and Ross 1982; Worrall 1990). Thinking of others is a characteristic of 'ideal' femininity. Guilty pleas provide an indication of remorse and as such concern with regard to the impact of one's behaviour on others (White and Perrone 2005:155). A plea of guilty may be more beneficial to women than men because there is a higher expectation that women will show remorse.

In contrast, being convicted of multiple conviction counts may pose more of a challenge to femininity than a one-off offending incident. Multiple counts suggest sustained, and thus more serious, offending behaviour. Crime is symbolically masculine and when women offend, sentencing research shows that attempts are made to reconcile their criminality with the dominant bounds of femininity (Jeffries 2002b). The more serious the offence committed by a woman, the more difficult it is for this reconciliation to occur because perceptually the more masculine her behaviour has become. Women tend to appear in court for less serious offences with fewer counts - women who are convicted of multiple counts may, therefore, be judged as more dangerous and less reformable, than men in similar circumstances because they have flouted both the criminal law and exceeded the bounds of gender appropriate behaviour (Bishop and Frazier 1984:386). 


\section{Directions for future research}

Both the direct and interaction sex effects found in the current sentencing research may, therefore, come down to the differing social circumstances and expectations that men and women bring to the courtroom. However, whether or not this is the case is beyond the scope of this research methodology, because this information was not available in OCSAR's court database. The explanations put forward above are speculative and require further work.

First, it is imperative that future quantitative research seeking to explore the relationships between sex and sentencing (both direct and interactive) should include social history measures (eg victimisation, health, child-care responsibilities etc). This would help to determine what if any role these factors play in male versus female sentencing.

Second, qualitative methods may need to be utilised alongside quantitative techniques. Quantitative research focuses primarily on exploring whether or not disparities in sentencing outcomes exist. Little is known about how judges in Australia perceive female offenders and their histories, and how they interpret the circumstances of women in rationalising their sentencing decisions (see Daly 1994:264-5). Qualitative analyses might include discourse analyses of judges' sentencing remarks and interviews with judges concerning their sentencing philosophies and practices.

\section{References}

Allen H (1987) Justice Unbalanced: Gender, Psychiatry and Judicial Decisions Open University Press Philadelphia

Australian Bureau of Statistics (1997) Australian Standard Offence Classification (ASOC), 1997 cat no 1234.0 ABS Canberra

Australian Bureau of Statistics (2009a) Criminal Courts, Australia, 2008-09 cat no 4513.0 ABS Canberra

Australian Bureau of Statistics (2009b) Prisoners in Australia, 2009 cat no 4517.0 ABS Canberra

Australian Institute of Criminology (2009) Australian crime: Facts and figures AIC Canberra

Bishop DM and Frazier CE (1984) 'The Effects of Gender on Charge Reduction' Sociological Quarterly vol 25 no 3 pp 385-96

Bushway S, Johnson BD and Slocum LA (2007) 'Is the Magic Still There? The Use of the Heckman Two-Step Correction for Selection Bias in Criminology' Journal of Quantitative Criminology vol 23 no 2 pp 151-78

Daly K (1987a) 'Structure and Practice of Familial-Based Justice in a Criminal Court' Law \& Society Review vol 21 no 2 pp 267-90

Daly K (1987b) 'Discrimination in the Criminal Courts: Family, Gender, and the Problem of Equal Treatment' Social Forces vol 66 no 1 pp 152-75

Daly K (1989) 'Neither Conflict Nor Labeling Nor Paternalism Will Suffice: Intersections of Race, Ethnicity, Gender, and Family in Criminal Court Decisions' Crime and Delinquency vol 35 no 1 pp 136-68 
Daly K (1994) Gender, Crime and Punishment Yale University Press New Haven

Daly K and Bordt RL (1995) 'Sex Effects and Sentencing: An Analysis of the Statistical Literature' Justice Quarterly vol 12 no 1 pp 142-75

Douglas R (1987) 'Is Chivalry Dead? Gender and Sentence in the Victorian Magistrates' Courts' Australian and New Zealand Journal of Sociology vol 23 no 3 pp 343-57

Farrington DP and Morris AM (1983) 'Sex, sentencing and reconviction' British Journal of Criminology vol 23 no 3 pp 229-48

Frazier CE, Bock W and Henretta JC (1983) 'The Role of Probation Officers in Determining Gender Differences in Sentencing Severity' Sociological Quarterly vol 24 no 2 pp 305-18

Jeffries S (2002a) 'Does Gender Really Matter? Criminal Court Decision Making in New Zealand' New Zealand Sociology vol 17 no 1 pp 135-49

Jeffries S (2002b) 'Just or Unjust? Problematising The Gendered Nature of Criminal Justice' Women's Studies Journal vol 18 no 1 pp 24-41

Jeffries S (2004) 'Newsmaking Criminology or Infotainment Criminology? A Decontextualised, Fragmented and Misconstrued Critique' Australian and New Zealand Journal of Criminology vol 37 no 2 pp 286-95

Jeffries S and Bond C (2009) 'Does Indigeneity Matter? Sentencing Indigenous Offenders in South Australia's Higher Courts' Australian and New Zealand Journal of Criminology vol 42 no 1 pp 47-71

Jeffries S, Fletcher G and Newbold G (2003) 'Pathways to Sex-Based Differentiation in Criminal Court Sentencing' Criminology vol 41 no 2 pp 329-53

Johnson BD (2003) 'Racial and Ethnic Disparities in Sentencing Departures Across Modes of Conviction' Criminology vol 41 no 2 pp 449-89

Kruttschnitt C (1982) 'Women, Crime, and Dependency: An Application of the Theory of Law' Criminology vol 19 no 4 pp 495-513

Kruttschnitt C (1984) 'Sex and Criminal Court Dispositions: The Unresolved Controversy' Journal of Research in Crime and Delinquency vol 21 no 3 pp 213-32

Kruttschnitt C and Green DE (1984) 'The Sex-Sanctioning Issue: Is it History?' American Sociological Review vol 49 no 4 pp 541-51

Lawrence JA and Homel R (1992) 'Sentencer and Offender Factors as Sources of Discrimination in Magistrates' Penalties for Drinking Drivers' Social Justice Research vol 5 no 4 pp 385-413

Mitchell O (2005) 'A Meta-Analysis of Race and Sentencing Research: Explaining the Inconsistencies' Journal of Quantitative Criminology vol 21 no 4 pp 439-66

Nagel I (1981) 'Gender Differences in the Processing of Criminal Defendants' in Morris A and Gelsthorpe L (eds) Women and Crime Cropwood Conference Series No 13 University of Cambridge Institute of Criminology Cambridge

Nagel I, Cardascia J and Ross CE (1982) 'Sex Differences in the Processing of Criminal Defendants' in Weisberg DK (ed) Women and the Law: The Social Historical Perspective Schenkman Books Cambridge 
Naylor B (1991) 'Sentencing Female Offenders in the Magistrates' Court: Preliminary Report on a Pilot Study' in Weiser Easteal P and McKillop S (eds) Women and the law: Proceedings of a conference held 24-26 September 1991 Australian Institute of Criminology Canberra

Naylor B (1993) Gender and Sentencing in the Victorian Magistrates' Courts: A Pilot Project Criminology Research Council Canberra

Spohn CC (2000) 'Thirty Years of Sentencing Reform: The Quest for a Racially Neutral Sentencing Process' in Criminal Justice 2000 Volume 3 Policies, Processes, and Decisions of the Criminal Justice System National Institute of Justice US Department of Justice Washington

Spohn C and Beichner D (2000) 'Is Preferential Treatment of Females Offenders a Thing of the Past? A Multisite Study of Gender, Race, and Imprisonment' Criminal Justice Policy Review vol 11 no 2 pp 149-84

Steffensmeier D, Kramer J and Streifel C (1993) 'Gender and Imprisonment Decisions' Criminology vol 31 no 3 pp 411-46

Steffensmeier D, Ulmer J and Kramer J (1998) 'The Interaction of Race, Gender, and Age in Criminal Sentencing: The Punishment Cost of Being Young, Black, and Male' Criminology vol 36 no 4 pp 763-97

Tjaden PG and Tjaden CD (1981) 'Differential Treatment of the Female Felon: Myth or Reality?' in Warren MQ (ed) Comparing Female and Male Offenders Sage Beverly Hills

Triggs S (1999) Sentencing in New Zealand: A Statistical Study Ministry of Justice Wellington

White R and Perrone S (2005) Crime and Social Control (2 $2^{\text {nd }}$ ed) Oxford University Press Melbourne

Wilkie M (1993) Sentencing Women: Pre-Sentence Reports and Constructions of Female Offenders Crime Research Centre University of Western Australia Perth

Worrall A (1990) Offending Women: Female Lawbreakers and the Criminal Justice System Routledge London

$\mathrm{Wu} \mathrm{J}$ and Spohn C (in press) 'Does an Offender's Age Have an Effect on Sentence Length? A Meta-Analytic Review' Criminal Justice Policy Review 